\section{Contributors}

Eleanor Brown is a single-handed principal at Cardiff Road Surgery in Fountain Ash in the South Wales Valleys

eleanor.brown@gp-w95623.wales. nhs.uk

James Pink is an associate academic fellow in the department of Primary Care and Public Health at

Cardiff University

pinkj@Cardiff.ac.uk

Francesco Carelli is professor of family practice at the University of Milan, Italy. Milan these days is rather better known for family medicine than for football

francesco.carelli@alice.it

\section{Mike Fitzpatrick}

fitz@easynet.co.uk

Seth Jenkinson is a GP who lives in Bradford's most palatial textile mill. Readers may remember his observation that if Stephen Hawking can work then no one can be prevented from work by illness sethjenkinson@yahoo.co.uk

Edin Lakasing is a GP in Chorleywood, Hertfordshire and tutor in General Practice to University College, Royal Free and St Mary's Hospital medical schools, London. In his spare time he writes, and had been Hotspur FC to win anything at all. And then, between submission and publication, his team wins the Carling Cup edin.Lakasing@chorleywoodhealth centre.nhs.uk

Zul Mirza is a consultant in Accident and Emergency at West Middlesex University Hospital, London. He was formerly a registrar in General Practice on the Watford Vocational Training Scheme. In his spare time, he has been waiting a long time for Liverpool FC to win the Premiership title. (That's quite enough about footie, Ed)

Lesley Morrison is a GP in Hawick in the Scottish Borders 3 days a week lesley@ljmorrison.fsnet.co.uk

Gervase Vernon is a GP in Dunmow in Essex

gervase@jth.demon.co.uk

Jeffrey Aronson's remarks on compliance and adherence, published in this column of the March issue of the BJGP, were originally circulated in a private email and not intended for publication. I would like to apologise for publishing without permission. Alec Logan

\title{
Dr Grumpy will see you now ...
}

My mother-in-law has just received a jury summons, which was forwarded to my wife by the old lady's care home, my wife having held her power of attorney for some years and now being engaged in managing her probate. It is rather sweet to think that our modern, technologicallyempowered state still thinks 94-year-old ladies, even live ones, might potentially be useful.

When I was young and naïve enough to give Workers Educational Association pre-retirement lectures I used to point out the curious fact that we don't just live to be parents, we live to be grandparents. It might have been different, I used to say, but it isn't, and there must be a reason. Evolution of course weeds out any characteristics which confer disadvantage to the species and if it were not an advantage for us to live beyond our immediate child-bearing years, we wouldn't. To anyone except whatever creationists are calling themselves at the moment, it is barn-door obvious that nature's cost-benefit analysis for and against older people in society works out well to the positive.

And the reasons are not hard to find. We are better off when a generation of more experienced people balances the energy, aggression, and impetuousity of libidinous youth. I am most certainly not advocating a return to the days when the decaying members of society exercised an automatic and unchallengeable tyranny, but I do suggest things today may have gone too far in the opposite direction. One of the consequences of the phenomenal changes in society, part social, part technological, which continue, following Moore's Law of microprocessor development, to accelerate, has been the disinheriting of the older generation from their traditional role as repositories of wisdom. But this same phenomenal change is the very reason why traditional wisdom has never been more vital. It is essential that experienced people stand back and try to understand what is happening to our society and speak out when they see things which they believe are not good.

An easy cop-out has emerged from what was originally a good, simple idea the television programme 'Grumpy Old Men'. This was followed quickly by 'Grumpy Old Women' and although the whole point of the show was that these people were hitting important nail after important nail on its important head, such manifest wisdom could only be presented on television if it was dressed up as a selfmockery of age. 'Grumpy Old Women Live returns for a third round of huffing, finger waggling, and fist shaking. Have you reached that certain age?' says the program's blurb, and so on, and so on. And so, whenever two or three are gathered together and the conversation turns, as it invariably does, to modern life, somebody sooner or later will say 'we are being grumpy old men!', everybody will laugh, shrug, and so the clutch between the truth of what is being said and any ambition to do something about it is lazily disengaged.

So, to take one example, when I read David Aaronovitch in the Times ${ }^{1}$ echoing Lord Darzi and arguing that 'It is unrealistic to have a cradle-to-grave GP ... Ignore the doctors. Polyclinics are the future.' I say no, you are wrong, polyclinics are the past, they were tried in Livingstone New Town, they were tried in Soviet Russia. And when the caption under the accompanying picture of Dr Finlay says 'That was then, this is now.' I say, well done, now you are right, your 'then' is a picture of warm, human interaction, which I well recognise and which I want for the future; your 'now' is nothing, a void perhaps because there wasn't room, or editorial courage, to depict a cold string of digits. And when Aaronovitch says he doesn't want a generalist doctor, thank you, I resist the temptation to quip that I don't want a generalist newspaper columnist. Because actually I do, as, unlike him, I have thought through the power and legitimacy of generalism.

I don't claim that these opinions should be accepted without question. Of course I don't. I expect them to be subjected to the same filters of intellectual scrutiny as any other ideas. But I do expect to be given credit for my experience, and not for it to be used as a cheap excuse for shrugging off my contribution.

\section{REFERENCE}

1. Aaronovitch D. Ignore GPs. Polyclinics are the future. Times 2008; 19 Feb. http://www.timesonline.co.uk/ tol/comment/columnists/david_aaronovitch/article 3393128.ece (accessed 11 Mar 2008).

DOI: 10.3399/bjgp08X280119 